\title{
Diet adaptability by a generalist herbivore: the case of brown hare in a Mediterranean agroecosystem
}

\author{
Christos Sokos ${ }^{1,2^{*}}$, Konstantinos Andreadis $^{1}$ and Nikolaos Papageorgiou ${ }^{1}$
}

\begin{abstract}
Background: Brown hares (Lepus europaeus) were collected before and after autumn rains from a mixed farmland and scrubland area. The age and sex of each specimen were determined, and microhistological technique was applied to analyze the stomach contents.

Results: Hares consumed a higher number of plant species in comparison with other studies in continental European farmlands. A different pattern in diet of hare was found, where from a partial herbivory, frugivory, and granivory during the dry period, hares turn to primarily herbivory during the wet period. An expansion of diet breadth and an increase in food consumption was found in the dry season. Farming contributes to the enrichment of diet especially during the dry season. Diet composition was differed between ages, but no significant difference was found between the two sexes.

Conclusions: Hare is a facultative generalist herbivore that adapts its diet to the seasonal vegetation changes. In Mediterranean ecosystems, the seeds, fruits, and grapes are important additions to the diet. Results suggest that during the dry period juveniles cannot exploit all the available food resources, such as fruits and seeds, as effectively as adults.
\end{abstract}

Keywords: Herbivore; Feeding ecology; Dietary breadth; Forage quality; Dietary specialization

\section{Background}

The main characteristics of Mediterranean ecosystems that are important for wildlife are the prolonged dry, hot period and high biodiversity (Blondel et al. 2010; Sokos et al. 2012). Flexibility in foraging is a typical response of herbivores to cope with seasonal differences in food availability and quality in the Mediterranean (Rueda et al. 2008). Mammals such as the brown hare (hereafter hare) have higher genetic diversity (Antoniou et al. 2013), a longer reproductive period (Antoniou et al. 2008), and a more diverse diet (Kontsiotis et al. 2011) in the Mediterranean than in more northern ecosystems of its distribution.

Studies about hare diet have found that factors which cause variability are the size of the studied area (Karmiris

\footnotetext{
* Correspondence: sokos@vet.uth.gr

${ }^{1}$ Laboratory of Wildlife and Freshwater Fisheries, School of Forestry and Natural Environment, Aristotle University of Thessaloniki, Thessaloniki GR-54124, Hellas (Greece)

${ }^{2}$ Research Division, Hunting Federation of Macedonia and Thrace, Ethnikis, Antistasis 173-175, GR-55134 Thessaloniki, Hellas
}

and Nastis 2010, Kontsiotis et al. 2011), the season (Chapuis 1990), and the vegetation of the area studied (Hulbert and Iason 1996; Kontsiotis et al. 2011). Moreover, when stomach contents are analyzed, high individual variability in the diet has been recorded (Katona et al. 2010). However, this variability has been poorly studied, even though differences in diet between sexes and ages are possible. For example, a greater propensity to disperse has been found in young male hares (Avril et al. 2011); males are more active in their movements and with larger home ranges than females (Zaccaroni et al. 2013), and microhabitat use may differ (Litvaitis 1990). The different physiological status between sexes and ages can also influence diet variability (Iason and Waterman 1988).

Additionally, in Mediterranean lowland farmland areas, the diet ecology of the hare is almost unknown. However, hare is an important species for hunting economy (Sokos et al. 2003) and has fundamental roles in natural processes such as seed dispersal (Izhaki and Ne'eman 1997) 
and being prey for threatened predator species (DelibesMateos et al. 2009). Information on hare diet would assist evaluations on the suitability of different ecotopes for hare and to design appropriate habitat improvement actions and agri-environmental measures (Sokos et al. 2012).

The hypothesis was made that hares adjust their diet in the wet and dry seasons and that adults and males consume more plant species or fewer, depending on differentiation in movements, experience, nutritional needs, and preferred plant availability. Therefore, this study aimed to (1) identify the plant taxa consumed by hare and (2) investigate any differences in diet composition and stomach content weight in relation to season, sex, and age. Moreover, the high plant diversity of the study area provides the opportunity to test how generalist the hare is in its diet.

\section{Methods}

\section{Study area}

The study took place in SW Hellas, $65 \mathrm{~km}$ southwest of the city of Patras. The investigation concentrated on a $12-\mathrm{km}^{2}$ area of Kyllini Peninsula $\left(37.884812^{\circ}, 21.138229^{\circ}\right)$. The area comprises an isolated hilly landscape with altitudes ranging from 20 to $130 \mathrm{~m}$. The climate is classified as Mediterranean with dry summers and mild and rainy winters, without snowfall. The mean annual precipitation is $817 \mathrm{~mm}$, and the mean annual air temperature is $16.8^{\circ} \mathrm{C}$. In this lowland Mediterranean area, the growing season for most plant species begins after the autumn rains.

The Kyllini Peninsula belongs to the vegetation subzone Quercion ilicis (Dafis 1973) and the vegetation comprises shrub-dominated maquis. Farmland covers $68.5 \%$ and shrubland $31.5 \%$. Agricultural fields of about 0.5 ha and shrublands create a diverse mosaic. The main cultivations are olive groves $60 \%$, water melons $10 \%$, citrus $8 \%$, winter cereals $6 \%$, maize $2 \%$, tomatoes $2 \%$, vineyards $1 \%$, other annual crops $2.5 \%$, plowed fields $3.5 \%$, and set-aside $5 \%$, whereas livestock grazing is limited, and the only wild herbivore present in the area is the hare (Sokos and Andreadis 2000).

\section{Reference slide collection}

A reference collection of slides of plant epidermis (leaves, stems, fruits, seeds) was prepared using Hertwig solution for discolouration and glycerin for preservation (Baumgartner and Martin 1939; Holechek 1982). Diagrams were drawn of all slides, and photographs were taken. A total of 162 plant species was collected (37 woody plants, 107 herbs, and 18 cultivated plant species) after vegetation survey of the area using sampling plots, thus the most plant species were recorded during the studied period (Sokos and Andreadis 2000).

\section{Hare collection}

Using a cynegetic index abundance, the population density was estimated at five hares $/ \mathrm{km}^{2}$ (Sokos and Andreadis 2000). Hares were harvested by legally licensed volunteer hunters. The authors declare that this study is based on legal hunting methods according the Hellenic Hunting Law (68719/3105/15-07-1997, Decision of the Ministry of Agriculture). A total of $n=48$ hares have been obtained by morning hunting during three hunting seasons 1997 to 1998, 1998 to 1999, and 1999 to 2000. Each hare was dissected to obtain one eye and the stomach. The organs were preserved for further analysis in $10 \%$ formalin. Hares were divided into two age classes: juveniles with dried eye lens weights $<235 \mathrm{mgr}$ and adults with dried eye lens $\geq 235$ mgr (Suchentrunk et al. 1991).

\section{Micro-histological analysis of stomach contents}

Each hare stomach was dissected, and small quantities of its contents were removed systematically from five points along the stomach axis. This method was applied as stomach content includes both newly grazed and reingested material that differentiates from the entrance of the stomach to the exit (pylorus). This is caused mainly due to caecotrophy during the day. As this study aimed to determine hare diet composition during all the feeding period, it was thought more appropriate to acquire samples from five different positions rather than one mixed sample (Sokos and Andreadis 2000; Kontsiotis et al. 2011).

Each content sample was washed through a sieve with pore size $0.5 \mathrm{~mm}$ (Brüll 1976; Frylestam 1986). The sample was then spread evenly on a glass slide, heat was applied together with Hertwig's solution, and finally, a coverslip was placed over the sample (Frylestam 1986). In the area of the coverslip $(22 \times 22 \mathrm{~mm}), 20$ systematically chosen fields were examined. Each field was defined by the microscope using $\times 100$ magnifications. The plant fragments observed in each field were used to identify the plant species (Holechek and Gross 1982b; Homolka 1987). Unidentified fragments were recorded according to their characteristics.

The method was tested using four caged rabbits, which had previously been fed known quantities of two or three different herb species and about $5 \mathrm{~h}$ after these were euthanized. Moreover, the first three hare stomachs were reanalyzed to ensure that the researcher's (first author) experience did not affect the results (Holechek and Gross 1982a).

Relatively large pieces of food originating from fruits (such as grapes and Pyrus amygdaliformis) and seeds could not be placed under the coverslip. For this reason, these were separated from the stomach contents, dried, weighed, and expressed as a percentage of the total dry weight of the stomach content. Sparks and Malechek 
(1968) and Holechek and Gross (1982b) refer that for microhistological analyses, percentage frequency of occurrence can be expressed as percentage weight and vice versa. Thus, the percentage frequency of fruit or seed occurrence was estimated using the equation $\mathrm{Fi}=(\mathrm{fi}$ * $\mathrm{w} 1 / 100+\mathrm{wi}) * 100 /(w 1+w i)$, where Fi: the total frequency of occurrence of fruit or seed, fi: the frequency of occurrence of fruit or seed found by microhistological analysis, w1: the dry weight of quantity analyzed, and wi: the dry weight of the fruit or seed quantity that was separated.

\section{Ecological and statistical analyses}

Diversity in diet was estimated using the ShannonWiener function ( $\mathrm{H}^{\prime} \log$ Base 10$)$, as it is more sensitive to changes of rare species (Krebs 1999). Food niche breadth (B) was estimated using Levins' index (Krebs 1999). The standardized Levins' index (BA) was also used with the formula: $\mathrm{BA}=(\mathrm{B}-1) /(n-1)$, where $\mathrm{B}$ is the Levins' index, and $n$ is the total number of plant taxa (lowest niche breadth $=0$; highest niche breadth $=1$ ). This estimate is more useful for comparing diets among different areas and seasons that may vary in the number of available palatable plant species. Additionally, some plant species are more abundant than others; therefore, the Hurlbert's niche breadth $\left(\mathrm{B}^{\prime}\right)$ was calculated only for herbs, incorporating the availability of herb species found as median of cover and frequency of occurrence in frame quadrats applied in the study area (Sokos and Andreadis 2000).

Following the Bray-Curtis method (Krebs 1999), a dendrogram of diet data was made using Biodiversity Pro software, version 2 (McAleece et al. 1997). To test for overall differences in diet composition, statistical comparisons were made using ANOSIM two-way crossed analyses on Bray-Curtis dissimilarity matrices (program Primer-e) using 999 permutations (Clarke and Warwick 1994). Where significant differences occurred, the plant taxa most responsible for the difference were determined using a two-way similarity of percentages analysis, SIMPER (Primer-e, Clarke and Warwick 1994).

Diet parameters were tested by either one or two factors between subjects ANOVA (Zar 1996). The nonparametric test Mann-Whitney $U$ was used when the assumptions of using the parametric tests were not met. Statistical analyses were performed using IBM SPSS 20.0 data analysis software. The level of significance was set to be $\alpha=0.05$.

\section{Results}

In total, 48 hares were collected during the period of 3 years; differences did not happen in natural vegetation and cultivations of the studied area, thus the hares of different years were grouped for further analyses. The hares were classified according the stage of vegetation, thus 26 hares were classified in the transitional period of vegetation from summer to winter (named dry season: 20 September to 9 November) where 1) winter plant species have not yet grown sufficiently, taking into account each studied year's plant phenology, and 2) summer plant species and fruits have not yet died down or desiccated completely. The remaining 22 hares were collected in the growing period for winter herbs and many shrub species (named wet season: 19 November to 6 January).

Identification of all examined fragments to species level was not possible (caecotrophy during the day is a reason). Moreover, morphological characteristics of some plant species which belong to the same genus or family are very similar and identification is difficult (Westoby et al. 1976; Homolka 1986). To lower the risk of incorrect identifications, species with high similarity, such as sprouting winter grasses, were grouped.

Microhistological analysis recognized 36 plant taxa (recognizable in the level of species, genus or family), of which 26 were dicotyledons and 10 were monocotyledons. Careful comparisons with the reference collection permitted the estimation that hares consumed about 63 plant species (58 plant species of the 162 examined microhistologically, and 5 more species which were not in the reference slide collection). The leaves and stems mostly eaten were from winter grasses (Avena sativa, Avena sp., Dasypyrum villosum, Bromus sterilis, Dactylis glomerata, Hordeum vulgare, Triticum aestivum, Lolium multiflorum), summer grasses (Echinochloa crus-galli, Eleusine indica, Paspalum distichum), and other grasses and forbs (Table 1). Significant quantities of Pyrus amygdaliformis fruits and seeds of cereals and other grasses were also observed (Table 1).

The most common plant species found between hares (above 25\% of specimens) were winter grasses, Cynodon dactylon, Convolvulus arvensis, summer grasses, Allium roseum, and Amaranthus sp. Overall diversity in the diet was higher in the dry season (29 taxa and $\mathrm{H}^{\prime}=1.247$ ) than in the wet season (27 taxa and $\mathrm{H}^{\prime}=0.87$ ). Similarly, the overall dietary breadth indices were higher in the dry season (Table 1).

The number of plant taxa consumed by each individual animal does not differ with season, age or sex $(p>$ $0.176)$. However, diversity in diet $\mathrm{H}^{\prime}$ and dietary breadth indices $\mathrm{B}$ and BA were higher in dry than wet seasons $(p<0.046)$, higher in juveniles than adults in the dry season $(p<0.014)$, and higher in adults than juveniles in the wet season $(p<0.05)$. Hurlbert's niche breadth $\left(\mathrm{B}^{\prime}\right)$ was used only for herbs (monocotyledons and dicotyledons) and did not reveal any significant differences concerning season, age, or sex $(p>0.101)$.

In the dry season, monocotyledons and dicotyledons have similar abundances in diets followed by fruits, seeds, 
Table 1 Mean frequency of occurrence (F\%) and percentage of hare stomachs containing a certain plant taxa ( $n \%$ )

\begin{tabular}{|c|c|c|c|c|c|c|}
\hline \multirow[t]{2}{*}{ Species or group of species } & \multicolumn{2}{|c|}{ Dry season $(n=26)$} & \multicolumn{2}{|c|}{ Wet season $(n=22)$} & \multicolumn{2}{|c|}{ Total $(n=48)$} \\
\hline & $\mathrm{F} \%$ & $n \%$ & $\mathrm{~F} \%$ & $n \%$ & $\mathrm{~F} \%$ & $n \%$ \\
\hline Monocotyledons & 36.34 & 100 & 50.57 & 100 & 42.86 & 100 \\
\hline Grasses & 32.38 & 100 & 49.52 & 100 & 40.24 & 100 \\
\hline Winter grasses & 17.31 & 84.62 & 43.44 & 100 & 29.29 & 91.67 \\
\hline Summer grasses & 6.63 & 61.54 & 0.12 & 18.18 & 3.65 & 41.67 \\
\hline Cynodon dactylon & 2.12 & 53.85 & 3.49 & 81.82 & 2.75 & 66.67 \\
\hline Brachypodium sp. & 3.02 & 15.38 & 1.18 & 9.09 & 2.18 & 12.50 \\
\hline Setaria sp. & 1.94 & 15.38 & & & 1.05 & 8.33 \\
\hline Cynosurus echinatus & 0.35 & 15.38 & 1.03 & 18.18 & 0.66 & 16.67 \\
\hline Sorgum halepense & 0.19 & 23.08 & & & 0.10 & 12.50 \\
\hline Unidentified grasses & 0.82 & 46.15 & 0.26 & 18.18 & 0.56 & 33.33 \\
\hline Other monocotyledons & 3.96 & 38.46 & 1.05 & 27.27 & 2.62 & 33.30 \\
\hline Cyperus rotundus & 2.67 & 7.69 & & & 1.45 & 4.17 \\
\hline Allium roseum & 0.48 & 23.08 & 0.95 & 36.36 & 0.69 & 29.16 \\
\hline Unidentified monocotyledon & 0.81 & 7.69 & 0.1 & 9.09 & 0.48 & 8.33 \\
\hline Dicotyledons & 36.29 & 100 & 43.4 & 90.91 & 39.55 & 95.80 \\
\hline Medicago sp. & & & 20.24 & 45.45 & 9.28 & 20.83 \\
\hline Convolvulus arvensis & 5.27 & 46.15 & 7.96 & 36.36 & 6.50 & 41.67 \\
\hline Amaranthus sp. & 9.30 & 46.15 & & & 5.04 & 25.00 \\
\hline Urospermum picroides & 2.76 & 7.69 & 0.92 & 9.09 & 1.92 & 8.33 \\
\hline Brassicaceae & & & 2.77 & 36.36 & 1.27 & 16.67 \\
\hline Malva sp. & 0.63 & 7.69 & 0.82 & 18.18 & 0.72 & 12.50 \\
\hline Cichoriaceae & 1.37 & 23.08 & & & 0.74 & 12.50 \\
\hline Sonhcus sp. & & & 1.49 & 9.09 & 0.68 & 4.17 \\
\hline Solanum nigrum & 0.66 & 3.84 & & & 0.36 & 4.17 \\
\hline Verbascum sp. & 0.50 & 7.69 & 0.219 & 18.18 & 0.37 & \\
\hline Senecio vulgaris & 0.33 & 3.84 & 1.05 & 27.27 & 0.66 & \\
\hline Trifolium sp. & 0.33 & 7.69 & 0.05 & 9.09 & 0.20 & 8.33 \\
\hline Vicia sp. & 0.08 & 7.69 & 0.14 & 9.09 & 0.11 & 8.33 \\
\hline Ornithopus compressus & 0.22 & 7.69 & & & 0.12 & 4.17 \\
\hline Anthemis arvensis & 0.16 & 7.69 & & & 0.09 & 4.17 \\
\hline Daucus carota & & & 0.18 & 9.09 & 0.08 & 4.17 \\
\hline Calendula arvensis & & & 0.10 & 4.54 & 0.05 & 4.17 \\
\hline Oxalis pes-caprae & & & 0.06 & 4.54 & 0.03 & 4.17 \\
\hline Unidentified dicotyledon 1 & 0.11 & 3.84 & 0.05 & 4.54 & 0.08 & 8.33 \\
\hline Unidentified dicotyledon 2 & 6.74 & 15.38 & 0.28 & 18.18 & 3.78 & 16.67 \\
\hline Unidentified dicotyledon 3 & 1.07 & 23.07 & & & 0.58 & 12.50 \\
\hline Unidentified dicotyledon 4 & & & 0.96 & 4.54 & 0.44 & 4.17 \\
\hline Unidentified dicotyledon 5 & 0.75 & 23.07 & 0.33 & 4.54 & 0.55 & 16.67 \\
\hline Unidentified dicotyledons & 6.01 & 76.92 & 5.78 & 90.91 & 5.90 & 83.33 \\
\hline Fruits, seeds, and barks & 25.91 & 92.31 & 5.54 & 81.82 & 16.57 & 87.50 \\
\hline Pyrus amygdaliformis & 4.56 & 15.38 & 1.72 & 18.18 & 3.26 & 16.67 \\
\hline Vitis vinifera & 2.70 & 7.69 & & & 1.46 & 4.17 \\
\hline Olea europaea & 0.27 & 7.69 & & & 0.15 & 4.17 \\
\hline
\end{tabular}


Table 1 Mean frequency of occurrence (F\%) and percentage of hare stomachs containing a certain plant taxa ( $n \%)$ (Continued)

\begin{tabular}{|c|c|c|c|c|c|c|}
\hline Unidentified dicotyledons & 8.47 & 76.92 & 3.30 & 63.64 & 6.10 & 70.83 \\
\hline Grasses & 9.91 & 38.46 & & & 5.37 & 20.83 \\
\hline Unidentified & 1.47 & 69.23 & 0.49 & 18.18 & 1.02 & 45.83 \\
\hline Taxa number & \multicolumn{2}{|c|}{29} & \multicolumn{2}{|c|}{27} & \multicolumn{2}{|c|}{36} \\
\hline Mean \pm SE of taxa number & \multicolumn{2}{|c|}{$7.07 \pm 0.4$} & \multicolumn{2}{|c|}{$6.54 \pm 0.54$} & \multicolumn{2}{|c|}{$6.83 \pm 0.33$} \\
\hline$H^{\prime}$ & \multicolumn{2}{|c|}{1.247} & \multicolumn{2}{|c|}{0.86} & \multicolumn{2}{|c|}{1.188} \\
\hline Mean $\pm \mathrm{SE}$ of $\mathrm{H}^{\prime}$ & \multicolumn{2}{|c|}{$0.68 \pm 0.023$} & \multicolumn{2}{|c|}{$0.56 \pm 0.048$} & \multicolumn{2}{|c|}{$0.63 \pm 0.027$} \\
\hline B & \multicolumn{2}{|c|}{12.84} & \multicolumn{2}{|c|}{4.1} & \multicolumn{2}{|c|}{8.46} \\
\hline Mean \pm SE of $B$ & \multicolumn{2}{|c|}{$3.76 \pm 0.19$} & \multicolumn{2}{|c|}{$3.03 \pm 0.31$} & \multicolumn{2}{|c|}{$3.42 \pm 0.18$} \\
\hline BA & \multicolumn{2}{|c|}{0.36} & \multicolumn{2}{|c|}{0.106} & \multicolumn{2}{|c|}{0.186} \\
\hline Mean \pm SE of $B A$ & \multicolumn{2}{|c|}{$0.34 \pm 0.017$} & \multicolumn{2}{|c|}{$0.27 \pm 0.027$} & \multicolumn{2}{|c|}{$0.31 \pm 0.016$} \\
\hline$B^{\prime}$ & \multicolumn{2}{|c|}{0.177} & \multicolumn{2}{|c|}{0.076} & \multicolumn{2}{|c|}{$-^{a}$} \\
\hline Mean \pm SE of $B^{\prime}$ & \multicolumn{2}{|c|}{$0.136 \pm 0.032$} & \multicolumn{2}{|c|}{$0.114 \pm 0.025$} & \multicolumn{2}{|c|}{$0.126 \pm 0.021$} \\
\hline
\end{tabular}

Mean frequency of occurrence (F\%) and percentage of hare stomachs containing a certain plant taxa ( $n \%)$ in the dry and wet seasons. Diversity and food niche breadth indices were calculated according to the mean frequencies of occurrence. Hurlbert's niche breadth ( $B^{\prime}$ ) was applied only to herbs.

${ }^{\mathrm{a}} \mathrm{B}$ ' was not calculated for the pooled data, due to the difference of availability of herb species between the two seasons.

and barks (Table 2). In the wet season, hares ate more monocotyledons. In the dry season, juveniles ate more dicotyledons than adults $(F 1,25=11.9, p=0.002)$, and the adults ate more fruits and seeds $(F 1,25=11.9, p=0.0001)$. Stomach content dry weight was higher in the dry season, in adults and females, but the difference was significant only for season ( $U$ test, $p=0.021$ ).
The results of the Bray-Curtis method for the diet of the hares according to the seasons, ages, and sexes can be seen in Figure 1. Juveniles of the dry season had the lowest similarity values in diet when compared to the other groups. Adult females of the dry season begin the consumption of winter grasses and cereals earlier and thus increase the similarity with wet season groups.

Table 2 Mean \pm SE of frequency of occurrence (F\%) for the main food categories

\begin{tabular}{|c|c|c|c|c|}
\hline Hare groups & Monocotyledons & Dicotyledons & Fruits, seeds, and barks & Stomach content dry weight \\
\hline \multicolumn{5}{|l|}{ Dry } \\
\hline \multicolumn{5}{|l|}{ Sex } \\
\hline Males & $35.37 \pm 4.1$ & $46.5 \pm 8.5$ & $15.56 \pm 7.6$ & $13.8 \pm 3.03$ \\
\hline Females & $36.97 \pm 5.4$ & $29.9 \pm 5$ & $32.36 \pm 4$ & $19.1 \pm 2.3$ \\
\hline \multicolumn{5}{|l|}{ Age } \\
\hline Juveniles & $38.2 \pm 4.9$ & $49.3 \pm 5.6^{c}$ & $10.2 \pm 3.08^{\mathrm{e}}$ & $14.8 \pm 2.03^{*}$ \\
\hline Adults & $34.2 \pm 4.1$ & $21.1 \pm 5^{d}$ & $44.21 \pm 3.55^{f}$ & $19.6 \pm 2.75$ \\
\hline Total & $36.36 \pm 3.2^{\mathrm{a}}$ & $36.27 \pm 4.7$ & $25.9 \pm 4.1^{9}$ & $17.8 \pm 1.93^{i}$ \\
\hline \multicolumn{5}{|l|}{ Wet } \\
\hline \multicolumn{5}{|l|}{ Sex } \\
\hline Males & $36.5 \pm 7.7$ & $59.52 \pm 6.8$ & $2.4 \pm 0.065$ & $9.75 \pm 0.43$ \\
\hline Females & $56.3 \pm 5.4$ & $37.8 \pm 5.7$ & $5.6 \pm 1.13$ & $12.78 \pm 0.92$ \\
\hline \multicolumn{5}{|l|}{ Age } \\
\hline Juveniles & $52.6 \pm 10.8$ & $41.9 \pm 11.7$ & $5.51 \pm 1.5$ & $10.25 \pm 1.29$ \\
\hline Adults & $49.8 \pm 5.7$ & $44.6 \pm 5.85$ & $4.73 \pm 1.3$ & $13.36 \pm 0.9$ \\
\hline Total & $50.85 \pm 5.2^{b}$ & $43.6 \pm 5.5$ & $5 \pm 0.96^{h}$ & $12.23 \pm 0.8^{j}$ \\
\hline
\end{tabular}

Mean \pm SE of frequency of occurrence $(F \%)$ for the main food categories in the diet of 48 examined hares, and stomach content dry weight (g) per season, age, and sex.

*Two leverets were excluded from the stomach content dry weight analysis as their stomachs contained milk.

In each column, the paired letters (ab, cd, ef, gh, ij) indicate significant differences at the 0.05 level. 

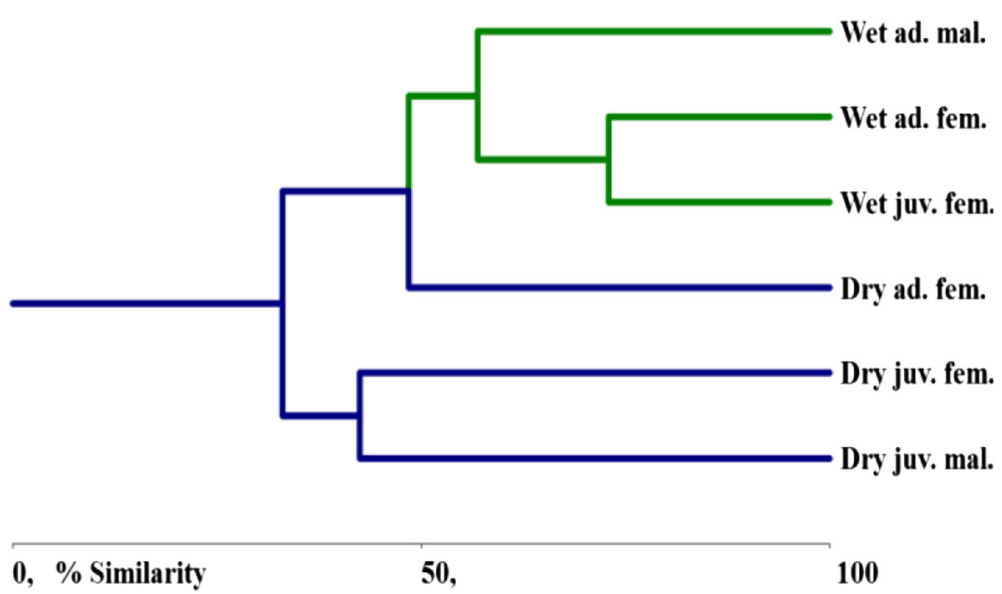

Figure 1 Dendrogram of Bray-Curtis percentage similarities for the diet composition (categories Wet juv. mal. and Dry ad. mal. were not included in sample). Juveniles of dry season had the lowest similarity values.

The ANOSIM two-way crossed analysis found a significant difference in the dietary composition between seasons (Global $\mathrm{R}=0.299, p=0.002$ ) and a marginal difference between ages (Global $\mathrm{R}=0.158, p=0.054$ ). The dietary composition between sexes was not significantly different (Global $\mathrm{R}=0.183, p=0.098$ ). The SIMPER analysis showed that the dissimilarity in diet between dry and wet seasons was a result of an increased prevalence of winter grasses and Medicago sp. in wet season and a decreased prevalence of seeds of grasses and cereals, C. arvensis, Amaranthus sp., and fruits of Pyrus amygdaliformis in comparison with the dry season. In the case of ages, the dissimilarity was caused by the higher consumption by adults of winter grasses, seeds, and fruits of Pyrus amygdaliformis and a lower consumption of Amaranthus sp. and summer grasses in comparison with juveniles.

\section{Discussion}

According to Holechek (1982), the microhistological analysis gives satisfactory results. However, one weakness is the differential fragmentation and digestion between plant species which influences the frequencies of occurrence. Thus, it is possible to observe an overestimation of grasses (McInnis et al. 1983). This was one of the reasons that stomach analysis was preferred over fecal analysis, as it is considered a more accurate method of determining the diet of herbivores, although Homolka (1986) did not find significant differences. However, if hares consume a considerable amount of seed and fruits, then diet is better studied using stomach contents (Green et al. 2013).

In many stomachs, a considerable amount of large food pieces by fruits and seeds were observed. Separating and dry weighting fruit and seed content permitted a more accurate estimation of their consumption. This may explain the reason why a higher percentage of fruit and seed in diet of hare in the dry season was found compared to other studies in Mediterranean (Sfougaris et al. 2006; Paupério and Alves 2008; Kontsiotis et al. 2011).

Diet analysis revealed that hares in the study area consume mainly wild plant species (except cereals and grapes). Many studies have revealed that hares that feed in farmlands prefer wild herbs over cultivated plants (Brüll 1976; Frylestam 1986; Reichlin et al. 2006). The mosaic landscape permits hares to access many wild plant species, so any impact to agricultural production is limited at this period. Moreover, farming contributes to the enrichment of a hare's diet with plants such as $C$. arvensis and Amaranthus spp. These plant species can be found growing within the irrigated crops such as watermelon. Grapes from the vineyards were also consumed. In one pregnant adult female's stomach, large pieces of grapes ( $6 \mathrm{~g}$ dry weight) were found, and these comprised $20.7 \%$ of the total dry weight of the stomach content.

The number of identified plant taxa per stomach was 6.8 and was higher than in a study in Denmark where the mean number of plant taxa found in each stomach was 3 (Hansen 1996). This information is not provided by other authors. Although we examined a smaller number of hare stomachs in comparison with other studies in more northern European farmlands (Frylestam 1986; Hansen 1996; Reichlin et al. 2006; Katona et al. 2010), we found a higher number of plant species eaten by hares. In comparison with studies carried out in the Mediterranean, we found more plant taxa than Karmiris and Nastis (2010) in their small shrubland study area (300 ha). On the contrary, Sfougaris et al. (2006) and Kontsiotis et al. (2011) found a remarkably higher number of identified plant taxa when examining the autumn and winter diet of 318 and 217 hares, respectively. However, these hares were collected from broad geographical, mainly upland, study areas of thousands of $\mathrm{km}^{2}$. The larger number of plant taxa they 
recorded is probably caused by the larger number of hares examined and the larger study areas, as the standardized Levins' niche dietary breadth index (BA) calculated by Kontsiotis et al. (2011) was lower than that of this study. The Shannon-Wiener function $\left(\mathrm{H}^{\prime}\right)$ calculated in this study was approximately two times higher than that of studies conducted in continental climates (Puig et al. 2007; Katona et al. 2010), whereas it was similar with that of other studies conducted in the Mediterranean (Karmiris and Nastis 2010; Kontsiotis et al. 2011).

Grasses (Poaceae) constituted the bulk of the diet, and similar results were found in continental Europe (e.g., Katona et al. 2010) and mountainous and shrubland areas in the Mediterranean. In our farmland study area, grasses (leaves and stems) accounted for $40.24 \%$ of the diet and seeds of grasses accounted for $5.37 \%$. Sfougaris et al. (2006) refer a total percentage of $36 \%$ of grasses in examined stomachs. Kontsiotis et al. (2011) refer that in examined stomachs, leaves and stems accounted for $24 \%$ of the diet and seeds accounted for $2.1 \%$. In two studies where feces were examined (Paupério and Alves 2008; Karmiris and Nastis 2010), a considerably higher total percentage of grasses was found, about $65 \%$.

In this study, a higher percentage of grass seeds (5.37\%) was found to be eaten during the dry period. This is probably due to the cereal stubble fields present in the study area and the applied method of separating large food pieces. Indeed, one hare stomach contained a huge piece of starch (16 g dry weight) by grass seeds that comprised $40.5 \%$ of the total dry weight of the stomach content. A high percentage of grass seeds (9\%) was also found in stomachs examined by Katona et al. (2010).

Hares adapt their diet according to vegetation in each season. ANOSIM analysis indicated that the diet composition between the two seasons differs significantly, and SIMPER analysis showed that seeds, fruits, C. arvensis, and Amaranthus spp. consumed in the dry season were replaced by winter grasses and Medicago spp. in the wet season. Higher consumption of grasses in winter has been found in continental Europe (e.g., Reichlin et al. 2006), whereas in yearround studies in Mediterranean mountainous and shrubland areas, the consumption of grasses was also found to increase slightly in winter (Paupério and Alves 2008; Karmiris and Nastis 2010).

Foraging theory refers an expansion of diet breadth (Pianka 2000) and an increase in food consumption (Sinclair et al. 1982; Rogers and Sinclair 1997) when the availability of nutritious food decreases. Similarly, diet breadth may be dependent on the distribution of preferred plant species in space. When few preferred plant species are available in sufficient quantity and distributed evenly in space, herbivores do not need to search and to consume more plant species (Stephens and Krebs 1986; Shipley et al. 2009). In this study, an expansion of diet breadth in the dry season was found, mainly due to the consumption of seeds and fruits. Moreover, stomach content dry weight was higher in the dry than in the wet season, indicating an increase in food consumption. These two events are indications of the nutritional reduction of herbaceous plants at the end of the dry season. Indeed, most herbs are in a mature stage in the end of the dry season, something that decreases their forage quality. Simultaneously, fruits of woody plants ripen, and seeds of many grasses and cereals provide nutritious food.

Moreover, in our study area, hare food resources are patchier during the dry season than in the wet season where grasses, the main food source, grow abundantly throughout the study area after the rains. In the dry season, cereal fields, fruit trees, vineyards, and irrigated crops are all potential feeding grounds and each contains different plant species. It is assumed that each individual hare cannot visit all these feeding grounds in one night. Therefore, dietary niche breadth expands further in the dry season in comparison with the wet season but only when overall values are compared and not the mean values of individual hares $(70.5 \%$ overall diet expansion vs. $20.6 \%$ diet expansion of mean individuals, according to BA in Table 1).

The expansion of diet breadth to include woody plants has previously been found for hare in colder climates, when the ground is covered by snow and herbaceous vegetation availability is decreased (Rödel et al. 2004; Green et al. 2013). We found evidence that a similar diet breadth expansion occurs in Mediterranean climates during the warm and dry seasons, but in this case, the limiting factor is the drought that decreases the foraging quality of herbs. Indeed, the improved diet of hares following the rainy season may be reflected in reproduction rates. Until the end of October, none of the females collected were pregnant, whereas at the end of autumn, after the rains, $50 \%$ of the collected females were pregnant and during the winter this number increased to 85\%. A similar pattern was found in Crete by Antoniou et al. (2008).

Comparison of dietary parameters between age and sex classes is possible due to the relatively small study area considered, the similar landscape mosaic and vegetation across the study area, and the ability of hares to disperse more than $500 \mathrm{~m}$ each night to find their preferred food (Homolka 1985; Kuijper and Bakker 2008) and to cover a nocturnal distance ranging between 1.39 and $6.02 \mathrm{~km}$ within their home range (Pepin and Cargnelutti 1994). A higher diversity in diet $\mathrm{H}^{\prime}$ and dietary breadth was found in juveniles than in adults in the dry season. Juveniles ate more dicotyledons than adults, and the adults ate more fruits and seeds. This indicates that juveniles cannot exploit all available food resources such as fruits and seeds. A reason may be is 
that fruits and seeds have more limited and patchy distributions. This is expected as juveniles have less knowledge of resource distribution (Gillingham and Bunnell 1989; Dahl 2005; Shipley et al. 2009) and, in some cases, are excluded by dominant hares (Lindlof 1978; Monaghan and Metcalfe 1985). The opposite seems to hold in the wet season when juveniles consume mainly nutritious and abundant winter grasses and have a narrower niche breadth than adults.

A second reason for fruit avoidance by juveniles may be because of the high concentration of secondary compounds contained in fruits (Jordano 2000). Iason and Waterman (1988) found that reproductively active females and leverets of Lepus timidus ate smaller proportions of heather Calluna vulgaris, than non-reproducing females and males, due to secondary compounds contained in this plant. However, in this study no differences were found between the sexes. Similarly, Homolka (1987) found no significant difference in diet composition between males and females.

Demeter and Matrai (1988) did not find differences in stomach content weights according to sex and age in Hungary, although Eley (1970) did find higher weights of female cape hares (Lepus capensis) than males. In this study, higher stomach content weights of adults and females were found, but they were not statistically significant. More female specimens collected in the wet season were pregnant and their higher energy requirements may force them to higher consumption (Hackländer et al. 2002).

The high plant diversity recorded in the area studied allows the examination of how specialist or generalist in diet the hare can be. Mammalian herbivores are classified as specialists if at least $60 \%$ of their diet consists of a single, distinctive plant genus or family (Shipley et al. 2009). In this study, the highest percentage of one single family was $49.52 \%$, the Poaceae, during the winter. Therefore, the grasses, even when their availability and palatability is high, do not render the hare as a specialist. However, in other studies, the hare behaves as a specialist on grasses consuming more than 60\% (Hansen 1996; Katona et al. 2010). According to (Shipley et al. 2009), the hare could be characterized as a facultative generalist as it is able to survive with a restricted diet breadth but prefers a broad dietary niche when the plant diversity is available.

\section{Conclusions}

The hare found to be a facultative generalist herbivore that adapts its diet to the seasonal vegetation changes. From a partial herbivory, frugivory, and granivory diet during the dry period, hares turn to primary herbivory during the wet period thus seeming to confirm the foraging theory for expansion of diet breadth and increase in food consumption when the availability of nutritious food decreases in the dry season due to the dying down of herbs. Therefore, in Mediterranean ecosystems, the seeds, fruits, and grapes are important additions to the diet. Stomach diet analysis seems to be more accurate in cases of frugivory and granivory than feces analysis, but additional studies are required to confirm this. During the wet season, hares probably feed on higher quality forage, and this factor appears to regulate reproduction rates; again, future studies should confirm this in Mediterranean lowland areas. Farming contributes to the enrichment of hares' diet, with cereals and grapes and other plant species that can be found growing within irrigated summer crops. Results suggest that during the dry period juveniles cannot exploit all the available food resources, such as fruits and seeds, as effectively as adults.

\section{Competing interests}

The authors declare that they have no competing interests.

\section{Authors' contributions}

CS and NP wrote the manuscript. CS carried out the statistical analyses. CS and KA carried out the laboratory analyses. CS participated in the sample collection. All authors read and approved the final manuscript.

Received: 9 December 2013 Accepted: 23 December 2014

Published online: 04 February 2015

\section{References}

Antoniou A, Kotoulas G, Magoulas A, Alves PC (2008) Evidence of autumn reproduction in female European hares (Lepus europaeus) from southern Europe. Eur J Wildl Res 54:581-587

Antoniou A, Magoulas A, Platis P, Kotoulas G (2013) Assessing the genetic landscape of a contact zone: the case of European hare in northeastern Greece. Genetica 141:1-18

Avril A, Leonard Y, Letty J, Peroux R, Guitton J-S, Pontier D (2011) Natal dispersal of European hare in a high-density population. Mam Biol 76:148-156

Baumgartner LL, Martin AC (1939) Plant histology as an aid in squirrel food habits studies. J Wildl Manage 3:266-268

Blondel J, Aronson J, Bodiou JY, Boeuf G (2010) The Mediterranean Region, Biological diversity in space and time. Oxford University Press, Oxford

Brüll V (1976) Nahrungsbiologishe Studien am Feldhasen in Schleswig - Holstein. In: Proceedings of the Poznan Symposium on the Ecology and Management of European hare populations. Ein Beitrag zu Äsungsverbesserung, Poland, p 1974

Chapuis $J$ (1990) Comparison of the diets of two sympatric lagomorphs, Lepus europaeus (Pallas) and Oryctolagus cuniculus (L.) in an agroecosystem of the lle-de-France. Z Säugetierkd 55:176-185

Clarke KR, Warwick RM (1994) Change in Marine Communities: an Approach to Statistical Analysis and Interpretation. Plymouth Marine Laboratory, Plymouth, UK

Dafis S (1973) Classification of vegetation in Greece, School of Forestry and Natural Environment. Aristotle University of Thessaloniki, Thessaloniki

Dahl F (2005) Distinct seasonal habitat selection by annually sedentary mountain hares (Lepus timidus) in the boreal forest of Sweden. Eur J Wild Res 51:163-169

Delibes-Mateos M, Farfan MA, Olivero J, Marquez AL, Vargas JM (2009) Long-term changes in game species over a long period of transformation in the Iberian Mediterranean landscape. Environ Manage 43:1256-1268

Demeter E, Matrai K (1988) Foods of the brown hare in a large scale cultivated plain area during November. Vadbiologia 2:85-90

Eley J (1970) Stomach contents, weights and volumes of cape hare. E Afr Wildl J $8: 270$

Frylestam B (1986) Agricultural land effects on the winter diet of brown hares (L. europaeus Pallas) in Southern Sweden. Mammal Rev 16:157-161

Gillingham MP, Bunnell FL (1989) Effects of learning on food selection and searching behaviour of deer. Can J Zool 67:24-32 
Green K, Davis NE, Robinson WA, McAuliffe J, Good RB (2013) Diet selection by European hares (Lepus europaeus) in the alpine zone of the Snowy Mountains, Australia. Eur J Wildl Res 59:693-703

Hackländer K, Tataruch F, Ruf T (2002) The effect of diet quality on lactation energetics in the European hare (Lepus europaeus). Physiol Biochem Zool 75:19-28

Hansen K (1996) Impact of modern farming on food supply of hares (Lepus Europaeus, Pallas) during the summer period. In: Proceedings of the I European Congress of Mammalogy. Lisboa: Museu Nacional de Historia Natural, Portugal

Holechek JL, Gross BD (1982a) Evaluation of different calculation procedures for microhistological analysis. J Range Manage 35:721-723

Holechek JL, Gross BD (1982b) Training needed for quantifying simulated diets from fragmented range plants. J Range Manage 35:644-647

Holechek JL (1982) Sample preparation techniques for microhistological analysis. J Range Manage 35:267-268

Homolka M (1985) Spatial activity of hares (Lepus europaeus). Fol Zool 34:217-226

Homolka M (1986) Comparison of two methods applied to study the food of Lepus europaeus. Fol Zool 35:199-206

Homolka M (1987) Problems associated with investigations into the diet of the European hare. Fol Zool 36:193-202

Hulbert IA, lason GR (1996) The possible effects of landscape change on diet composition and body weight of mountain hares Lepus timidus. Wildl Biol 2:269-273

lason GR, Waterman PG (1988) Avoidance of plant phenolics by juvenile and reproducing female mountain hares in summer. Funct Ecol 2:433-440

Izhaki I, Ne'eman G (1997) Hares (Lepus spp.) as seed dispersers of Retama raetam (Fabaceae) in a sandy landscape. J Arid Environ 37:343-354

Jordano P (2000) Fruits and frugivory. In: Fenner M (ed) Seeds: the Ecology of Regeneration in Natural Plant Communities. Commonwealth Agric. Bur. Intl, Wallingford, UK

Karmiris IE, Nastis AS (2010) Diet overlap between small ruminants and the European hare in a Mediterranean shrubland. Cent Eur J Biol 5:729-737

Katona K, Biro ZS, Szemethy L, Demeš T, Nyeste M (2010) Spatial, temporal and individual variability in the autumn diet of European hare (Lepus europaeus). Acta Zool Acad Sci Hung 56:89-101

Kontsiotis VJ, Tsiompanoudis A, Bakaloudis DE (2011) The influence of habitat structure on the European brown hare Lepus europaeus food habits in mountainous areas of Northern Greece. Mammalia 75:389-394

Krebs CJ (1999) Ecological Methodology, 2nd edn. Addison-Welsey Educational Publishers Inc., Menlo Park, CA

Kuijper DPJ, Bakker JP (2008) Unpreferred plants affect patch choice and spatial distribution of European brown hares. Acta Oecol 34:339-344

Lindlof B (1978) Aggressive dominance rank in relation to feeding by European hare. Viltrevy 10:146-157

Litvaitis JA (1990) Differential habitat use by sexes of snowshoe hares (Lepus americanus). J Mammal 71:520-523

McAleece N, Gage JDG, Lambshead PJD, Paterson GLJ (1997) BioDiversity Professional Statistics Analysis Software. Jointly developed by the Scottish Association for Marine Science and the Natural History. Museum, London

Mclnnis ML, Vavra M, Krueger WC (1983) A comparison of four methods used to determine the diets of large herbivores. J Range Manage 36:302-306

Monaghan P, Metcalfe NB (1985) Group foraging in wild brown hares: effects of resource distribution and social status. Anim Behav 33:993-999

Paupério J, Alves PC (2008) Diet of the Iberian hare (Lepus granatensis) in a mountain ecosystem. Eur J Wildl Res 54:571-579

Pepin D, Cargnelutti B (1994) Individual variations of daily activity patterns in radiotracked European hares during winter. Acta Theriol 39:399-409

Pianka ER (2000) Evolutionary Ecology, 6th edn. Benjamin-Cummings, Addison-Wesley-Longman, San Francisco

Puig S, Videla F, Cona MI, Monge SA (2007) Diet of the brown hare (Lepus europaeus) and food availability in northern Patagonia (Mendoza, Argentina). Mamm Biol 72:240-250

Reichlin T, Klansek E, Hackländer K (2006) Diet selection by hares (Lepus europaeus) in arable land and its implications for habitat management. Eur J Wildl Res 52:109-118

Rödel HG, VölkI W, Kilias H (2004) Winter browsing of brown hares: evidence for diet breadth expansion. Mamm Biol 69:410-419

Rogers AR, Sinclair ARE (1997) Diet choice and nutrition of captive snowshoe hares (Lepus americanus): interactions of energy, protein, and plant secondary compounds. Ecoscience 4:163-169
Rueda M, Rebollo S, Gálvez-Bravo L, Escudero A (2008) Habitat use by large and small herbivores in a fluctuating Mediterranean ecosystem: implications of seasonal changes. J Arid Environ 72:1698-1708

Sfougaris A, Toulia S, Giannakopoulos A (2006) Botanical composition of the diet of the hare (Lepus Europaeus) in the Thessaly, Greece. In: Proceedings of the 4th Pan-Hellenic Rangelands Conference. Hellenic Society for Range and Pasture Management, Volos, Hellas, 10-12 November 2004

Shipley LA, Forbey JS, Moore BD (2009) Revisiting the dietary niche: when is a mammalian herbivore a specialist? Integr Comp Biol 49:274-290

Sinclair ARE, Krebs CJ, Smith JNM (1982) Diet quality and food limitation in herbivores: the case of the snowshoe hare. Can J Zool 60:889-897

Sokos C, Andreadis K (2000) Elements of Ecology and Biology of the Brown Hare (Lepus Europaeus) in NW Peloponnese with Emphasis on the Impact of Farming on the Composition of Food. Dissertation, School of Forestry and Natural Environment, Aristotle University of Thessaloniki, Greece

Sokos C, Mamolos AP, Kalburtji KL, Birtsas PK (2012) Farming and wildlife in Mediterranean agroecosystems. J Nat Conserv 21:81-92

Sokos C, Skordas K, Birtsas P (2003) Valuation of hunting and management of brown hare (Lepus Europaeus) in rangelands. In: Proceedings of the 3rd Pan-Hellenic Rangelands Conference. Hellenic Society for Range and Pasture Management, Karpenissi, Hellas, 4-6 September 2002

Sparks DR, Malechek JC (1968) Estimating percentage dry weight in diets using a microscopic technique. J Range Manage 21:264-265

Stephens DW, Krebs JR (1986) Foraging Theory. Princeton University Press, Princeton, NJ

Suchentrunk F, Willing R, Hartl GB (1991) On eye lens weights and other age criteria of the brown hare (Lepus europaeus Pallas 1778). Z Säugetierkd 56:365-374

Westoby M, Rest GR, Web JA (1976) Problems with estimating herbivore diets by microscopically identifying plant fragments from stomachs. J Mammal $57: 167-172$

Zaccaroni M, Biliotti N, Buccianti A, Calieri S, Ferretti M, Genghini M, Riga F, Trocchi V, Dessi-Fulgheri F (2013) Winter locomotor activity patterns of European hares (Lepus europaeus). Mammal Biol 78(6):482-485

Zar JH (1996) Biostatistical Analysis. Prentice Hall, Englewood Cliffs, New Jersey

\section{Submit your manuscript to a SpringerOpen ${ }^{\odot}$ journal and benefit from:}

- Convenient online submission

- Rigorous peer review

- Immediate publication on acceptance

- Open access: articles freely available online

- High visibility within the field

- Retaining the copyright to your article

Submit your next manuscript at $>$ springeropen.com 